\title{
How do early career teachers value different types of support? A scale-adjusted latent class choice model
}

\author{
Paul F. Burke \\ Peter J. Aubusson \\ Sandra R. Schuck \\ John D. Buchanan \\ Anne E. Prescott
}

The first author is affiliated with Centre for the Study of Choice (CenSoC), University of Technology Sydney (UTS), PO Box 123, Broadway, NSW 2007, Australia. All other authors are affiliated with Centre for Research in Learning \& Change, Faculty of Arts and Social Sciences, University of Technology Sydney, PO Box 123, Broadway, NSW 2007, Australia

This paper is to be cited as:

Burke, Paul F., Peter J. Aubusson, Sandra R. Schuck, John D. Buchanan, and Anne E. Prescott. (2015) "How do early career teachers value different types of support? A scale-adjusted latent class choice model", Teaching and Teacher Education, 47 (April), 241-253.

DOI: doi:10.1016/i.tate.2015.01.005 


\title{
How Do Early Career Teachers Value Different Types of Support?
}

\section{A Scale-Adjusted Latent Class Choice Model}

\begin{abstract}
Using a discrete choice experimental approach and associated Scale-Adjusted Latent Class Model (SALCM), we quantify the relative value early career teachers (ECTs) place on various types of support in the form of affirmation, resources, collegial opportunities, mentoring, and professional development. ECTs with intentions to depart the profession, place greater relative value on the sharing of resources, cooperative teaching and planning, offsite discussions about classroom management and programming with mentors, and having a greater professional voice. In contrast, those with intentions to remain, place greater value on observation from and conversations about teaching with more experienced teachers at their school.
\end{abstract}

Keywords: beginning teachers; mentors; work environment; teacher retention; teacher induction; discrete choice experiment. 


\section{Introduction}

Teacher attrition is recognized as an enduring problem internationally. The Organization for Economic Co-operation and Development (OECD) reports concerns about the high rates of teacher attrition, particularly among beginning teachers, following its review of the profession across 25 countries (OECD, 2005). A large study of Chicago public school teachers found that only 30 percent of early career teachers (ECTs) remain at their original school after five years, consistent with average retention rates among beginning teachers reported for Illinois and the USA more broadly (Allensworth, Ponisciak, \& Mazzeo, 2009). However, these figures do not distinguish between those teachers leaving the profession entirely and those teachers migrating between schools, the latter described by Ingersoll and May (2012) as 'movers'. Nonetheless, Abdallah (2009) cites work in the USA to suggest that $50 \%$ of certified public school teachers leave the profession within their first five years of teaching. In the UK, $27 \%$ of qualifying teachers employed in the maintained (or state) sector are no longer teaching in this same sector after five years (House of Commons Education Committee, 2012). In Australia, the setting of the current research, the figure for those leaving the profession within their first five years of teaching appears to be around 10\% (Australian Government Productivity Commission, 2012; New South Wales Government, 2012). Departure rates within the first year of service among teachers employed in a permanent position have been relatively low and in decline in the Australian state of New South Wales, with resignation rates averaging 3.1\% over 2006 to 2012 (NSW DEC 2013). As such, this highlights how attrition rates can often be difficult to interpret because reports may refer only to departures of full-time employees, even though the majority of teachers may join the profession in a part-time or casual capacity (NSW CDE, 2012).

The literature identifies a relationship between forms of support available to ECTs and 
their intentions to stay in the profession (Boyd et al., 2011; Jones, Youngs, \& Frank, 2013). A 2007 Australian House of Representatives inquiry found that a key factor contributing to attrition among ECTs is inadequate support (House of Representatives Standing Committee on Education and Vocational Training, 2007). A follow up study by Queensland College of Teachers (QCT) revealed that more than $30 \%$ of survey respondents cited several factors as being very important in their decision to leave the profession, including: family or personal reasons; heavy workload; stress; student behavior; inadequate professional support; and, decisions to pursue employment outside the profession (QCT, 2013). Of particular significance was that respondents also indicated that the availability of certain forms of support may have influenced them to remain in the profession. Cited forms of support included planning and resource sharing with experienced teachers, an allocated and available mentor, access to online resources, and participation in an online community. It is unclear, however, which of these and other types of support are most valued by ECTs.

The aim of the current research is to understand what types of support are perceived as most desirable by ECTs. The study also investigates the preferred format, focus, and delivery for each type. Using a discrete choice experiment and associated choice model, we quantify the relative value ECTs place on various types of support such as affirmation, resources, collegial opportunities, mentoring, and professional development. Whilst all levels of support are likely to be nominated by ECTs as desirable if considered in isolation, the key outcome of the research approach used here is to understand which elements of a supportive teaching environment provide greater value to ECTs relative to others.

The systematic management of support systems for teachers, including those who are largely committed to the profession, can further minimize their negative experiences, including 
those that induce stress and emotional burnout (e.g., Hong, 2010; Liu \& Onwuegbuzie, 2012). Similarly, Bascia and Rottmann (2011) argue that improved working conditions of teachers can lead to multiple and reciprocal outcomes, such as enhanced opportunities for students to learn, which further strengthens teacher efficacy and commitment. Weiss (1999) found that a supportive workplace environment promoting collaboration, inclusiveness, and socialization is essential in fostering morale and commitment to the profession among ECTs. Hence, insights into what types of support are valued by ECTs have a number of implications for many outcomes such as improving retention, efficacy and student learning, while minimizing attrition and burnout.

The remainder of the paper is organized as follows. First, we briefly review the main types of support presented in the literature as conducive to positive outcomes such as retention, efficacy, and student learning. Second, we discuss the methodological framework that was used to examine the relative importance of various types of support among ECTs. Third, we present the experimental design and manner in which the supportive environment that teachers evaluated was undertaken. Fourth, we present the results of our choice model. Fifth, we discuss these results in terms of the broader implications for theory and practice in our understanding of teaching and teacher education. Finally, we outline the limitations of the research and avenues for future research.

\section{Review of the literature}

Many factors are important in impacting retention and attrition among ECTs (for extensive reviews see: Borman \& Dowling, 2008; Guarino, Santibanez, \& Daley, 2006; Johnson, 
Berg, \& Donaldson, 2005). However, many cited factors are beyond the control of the profession or employers, and therefore less open to organizational induced change (Jaramillo, 2012). These factors are particular to the teachers themselves, and include young people's needs to experience other career options (Mayer, 2006) and, particularly in the case of women, to start a family (Stinebrickner, 1998). Other factors that can be viewed as exogenous and impact retention relate to the sociodemographic characteristics of a school, student quality, as well as the affluence and crime rate of the surrounding area (Allensworth et al., 2009; Ladd, 2011). Some factors impacting teaching conditions and teacher retention are subject to external fiscal constraints, such as remuneration (e.g., Henry, Bastian, \& Smith, 2012; Stinebrickner, 1998) and class size (e.g., Darling-Hammond, 2006; Kirby, Berends, \& Naftel, 1999). These factors are often subject to national or state policy agenda, and therefore difficult to respond to at the local school level. Klassen and Anderson's (2009) comparison of teachers from 1962 to 2007 suggests that concerns about issues relating to teaching itself, such as workload and student behavior, have displaced issues pertaining to external sources, such as salary, buildings, and equipment. As a result, teachers are more likely to stay where they have supportive principals and cooperative colleagues who help them do their job well (Allensworth et al., 2009). For example, whilst beginning teachers report that their experiences are often influenced by their relationship with students and their ability to manage student behavior (e.g., Lukens, Lyter, \& Fox, 2004), a supportive environment to hold conversations regarding such issues can determine an ECT's ability to cope (Le Maistre \& Paré, 2010) whilst strengthening teacher efficacy, identification with their school, and commitment (Chan, Lau, Nie, Lim, \& Hogan, 2008).

For this reason, researchers of the experiences of ECTs stress the influence of interactions with colleagues, including mentors, and how formal and informal programs can minimize 
negative experiences, such as those relating to isolation (e.g., Abdallah, 2009; Ingersoll \& Strong, 2011). Questions of teacher efficacy are often traced back to the positive influence of induction programs (e.g., Darling-Hammond, 2006; Ewing \& Smith, 2003; Ingersoll \& Strong, 2011; Johnson, 2007; Smith \& Ingersoll, 2004). However, Jones et al. (2013) emphasize that school commitment requires ECTs to perceive a fit between their beliefs and practices with those of their colleagues.

Principals play a significant role in developing an organizational climate that is perceived by ECTs to be supportive of their work and those of their colleagues (Jones et al., 2013; Pogodzinski, Youngs, Frank, \& Belman, 2012). When the perceived organizational politics within a school appear to lead to the promotion of self-interests at the expense of organizational goals, teachers' identification with a school can be negatively impacted, which subsequently can impact teacher commitment (Chan et al., 2008). School leaders can be instrumental in shaping the experiences of ECTs by determining both their levels of participation in school management, and their potential to influence school climate and school effectiveness (e.g., Boyd et al., 2011; Johnson, 2007; Menon \& Athanasoula-Reppa, 2011; Pogodzinski et al., 2012). A related source of dissatisfaction among teachers is their perceptions about increasing workload, particularly in non-teaching responsibilities (Darling-Hammond, 2006). Novice teachers' perceptions of these factors form strong predictors of intentions to remain in or leave the profession.

Consequently, many problems facing ECTs are complex, and may require a combination of internal and external, cultural and structural changes. The above literature emphasizes the role of principals and colleagues in shaping the organizational climate of a school and supporting individual ECT experiences. Following their meta-analytic review of factors contributing to teacher retention, Borman and Dowling (2008) conclude that several specific forms of support 
for ECTs are amenable to change through policy, and can impact teacher decisions to move schools or leave the profession entirely. These include availability of mentoring support and professional development, teacher collegiality, executive support, and resources. Each specific element can contribute to providing a supportive teaching environment that is perceived to be of value by ECTs.

\subsection{Mentor support}

The availability and quality of mentoring has been shown to play a major role in the quality of ECTs' experiences, and is linked to retention rates. In a study investigating the factors that were most important in ECT satisfaction and assimilation into the work environment, support from mentor and colleagues was ranked highest (Alhija \& Fresko, 2010). Indeed, Le Maistre and Paré (2010) suggest that more experienced teachers have developed coping strategies for a variety of ill-defined problems, and that effective mentoring can help ECTs transcend mere survival. However, different aspects of mentoring can vary in their importance to ECTs with several studies indicating the most effective aspects include encouragement and opportunity to reflect on practice, support of risk-taking, provision of structured induction programs, opportunities for professional learning and a supportive school environment (Harrison, Dymoke, \& Pell, 2006; Löfström \& Eisenschmidt, 2009). Accordingly, it is useful to consider what facets of assigned formal mentoring support are most valued by teachers, and for this reason, such an investigation is part of the methodology of this study.

\subsection{Collegial support}

As noted above, one type of support found helpful by ECTs is that offered by colleagues. 
We distinguish this from support provided by an assigned mentor. Several researchers report that ECTs often seek informal support following a lack of satisfaction with their induction (Ewing \& Smith, 2003; Fenwick \& Weir, 2010). Researchers of the experiences of ECTs stress the influence of interactions with colleagues, which can minimize negative experiences, such as those relating to isolation (e.g., Abdallah, 2009; Ingersoll \& Strong, 2011). Maintaining a reflective dialogue among colleagues to consider ways to improve student learning, assessment and classroom behavior can foster teachers' identification with their school and teacher efficacy, which subsequently can impact commitment (Chan et al., 2008).

Collegial support is accorded equal importance with mentor support in contributing to ECTs' satisfaction and assimilation (Alhija \& Fresko, 2010). Further, if collaborative structures are built into induction programs, such collegial support meets the needs of many ECTs (Bickmore \& Bickmore, 2010). In geographically remote regions, for example in Australia, collegial community building supports teachers emotionally to manage the challenges experienced (Jarzabowski, 2003). Conversely, lack of collegial support can make the ECT experience challenging and draining. Some ECTs report that they must navigate their way through an inhospitable and sometimes hostile school culture where even interactions taking place in the staffroom and grounds of the school exemplify an unwelcoming environment (Schuck, Aubusson, Buchanan, \& Russell, 2012). It is therefore of value to examine the importance attributed to collegial support in ECTs' early experiences.

\subsection{Executive support}

Another factor highlighted in a number of studies of ECTs is the importance of executive support in the school. According to Tickle, Chang, and Kim (2011) a most significant predictor 
of ECTs' intention to stay in the profession and of their satisfaction in their new work environment was the support of the school executive, that is, the principals and senior leaders of the school. Similarly, Bickmore and Bickmore (2010), along with Fantilli and McDougall (2009), confirm the importance of the principal and school administrators in fostering growth and workplace satisfaction among ECTs. Kapadia, Coca, and Easton (2007) established that ECTs cited strength of school leadership and the extent of being welcomed by their faculty as the greatest influences on their decision whether or not to leave their school or the profession, with student behavior another strong predictor. Clearly, this is another important support mechanism to investigate in terms of its relative value for establishing an attractive teaching environment for ECTs.

\subsection{Support for Professional Development}

Professional development takes many forms. The effectiveness of different models of professional development is contested (Tytler, Smith, Grover, \& Brown, 1999). Much of the literature suggests that professional development in the form of courses, conducted off-campus, does not acknowledge the agency of teachers in their own learning, the contextual factors that might operate, and the need for experiential learning. As well, such courses tend not to be sustained and coherent (Garet, Porter, Desimone, Birman, \& Yoon, 2001). As a consequence, they are deemed to be less efficient and effective than other modes of professional development. However, ECTs also see benefits in such opportunities, as they provide freedom from interruption, time for discussion with other ECTs, and opportunities to gain valuable skills from professionals in behavior modification. Professional development run by the local district office has been found to offer valuable support for ECTs (Fantilli \& McDougall, 2009). So while 
induction programs that have clear professional development opportunities are regarded as valuable in enhancing the ECT's learning, the nature of the professional development warrants further investigation.

\subsection{Internal resources}

A feature of support for ECTs is the availability or absence of resources that are held by their school and which enhance the teaching of content or are directed at supporting particular needs of students. We label these 'internal resources' to emphasize the in-school location of such materials. Where a collegial community exists in the school, these resources are often shared or developed collaboratively (Jarzabowski, 2003). In other schools, resources are seen as the property of the teachers who have collected or developed them over the years, and often ECTs are unaware of their existence (Schuck et al., 2012). The privatization of resources is often a result or feature of a school culture devoid of collaboration. Collaboration resulting in team teaching, sharing of lesson ideas, and sharing of resources, is supportive of ECTs (Caspersen \& Raaen, 2014). Stormont, Reinke, and Herman (2011) note the general lack of awareness of ECTs about their schools' resources and programs, in this case, specifically to support students with emotional and behavioral problems. It seems important, therefore, to investigate teachers' views of the contribution of accessible internal resources to their job satisfaction.

\subsection{External resources}

Resources may be offered by the school or resources may be externally available online, or through an education resource bank. We label the latter type of resources 'external resources'. With the increased availability of online access to communities and resources, this source of 
support emerged as an important one to investigate further. There are numerous studies considering the value of online wikis and virtual learning environments to support teachers (e.g. Schuck, 2003; Hutchison \& Colwell, 2012). We were therefore interested to determine if external resources were deemed valuable by ECTs relative to other forms of support.

The discussion above highlights six categories of support that have been described as helpful to ECTs in the literature. These forms of support have been highlighted separately in many studies. Corbell, Reiman, and Nietfeld (2008) offer a similar categorization of support in their Perceptions of Success Inventory for Beginning Teachers (PSI-BT). The PSI-BT synthesizes the literature on teacher satisfaction, efficacy, and attrition to incorporate factors describing commitment, student outcomes, and efficacy. Their instrument emphasizes that beginning teachers' perceptions of success relate to various forms of support as previously highlighted including: (1) resource support, (2) administrative support, (3) mentor support, (4) collegial support, and (5) assignment and workload. In practice, each category of support has different modes, varying in terms of format, focus and delivery. In our study, we sought to explore these modes of support to examine their relative importance, as perceived by ECTs. Accordingly, a model has been developed to investigate these different levels of each mode of support, giving rise to a discrete choice experiment (DCE).

\section{Methodology}

\subsection{Methodological framework}

Whilst all levels of support are likely to be nominated by ECTs as desirable if considered in isolation, the key outcome of using a DCE is to understand which elements of a supportive 
teaching environment provide greater value to ECTs relative to others. To elicit this information, ECTs participating in an online survey made trade-offs among competing supportive factors in the context of a DCE. This approach overcomes concerns about the correlation between the factors under examination, which often occurs when evaluating the impact of factors using data based on actual experiences. The modeling approach is also particularly innovative in addressing issues relating to aggregation bias, making use of recent developments in latent class statistical models (Magidson \& Vermunt, 2007). The choice model predicts how modification of teachers' workplace conditions can optimize the perceptions of ECTs for a given support mechanism. It also accounts for how latent segments within this group may respond differently to such modifications. The choice modeling literature is well developed in areas such as transport, marketing, and health economics (e.g., Hess \& Daly, 2013). To our knowledge, there have been no reported studies employing DCEs and use of latent class modeling to examine the preference for different types of support among ECTs.

It has been commonplace to explore teachers' preferred workplace conditions, either qualitatively or through a variety of survey instruments, including rating scales. When using rating scales respondents consider each factor in isolation without being required to trade-off the relative benefit of each factor (Louviere \& Islam, 2008). A consequence of this is that such surveys often indicate that all factors are very important. A DCE addresses these issues by forcing respondents to trade-off among factors. DCEs also overcome issues arising from various response-style biases observed in rating scales (Baumgartner \& Steenkamp, 2001) and inconsistencies with tasks involving the allocation of points or percentages (Louviere \& Islam, 2008).

To understand preferences of ECTs for variations in support, we adopt a normative 
choice framework embedded in random utility theory (see Ben-Akiva \& Lerman, 1985). In this framework, people make choices to maximize utility by choosing the option they perceive as offering the greatest benefit. People are assumed to determine an overall utility value for each offering by giving a different importance weight to the features or factors describing them; a DCE is used to quantify these weightings.

In the DCE reported here, teachers were presented with teaching environments distinguished by the program of support offered to them consistent with variations identified in the literature, such as the nature of mentoring support, availability and type of resources, extent of collaboration, and opportunities for professional learning. Teachers were asked which teaching environment they would prefer, and whether they would prefer this choice over their current teaching conditions. In a DCE, to determine the relative importance of each factor and overcome issues of multicollinearity, the levels associated with each factor are systematically varied (Street \& Burgess, 2007). For example, in this study, the location of mentor interactions was varied across many levels (e.g., at school; at another school). Simultaneously, variation in the levels of other factors (e.g., resource access; development activities) occurred in an uncorrelated fashion to assess whether a particular type of support was of greater value relative to another. In this regard, this approach directly informs the research objective to understand which type of support is preferable from the perspective of ECTs. We now outline how the DCE was operationalized in greater detail.

\subsection{Designing the $\mathrm{DCE}$}

In the design of a DCE, the decision about which factors to include or exclude for evaluation is critical, yet the processes for doing so are not widely agreed upon (Islam, Louviere, 
$\&$ Burke, 2007). Most researchers use previous literature and focus groups, and although seldom, some use an interim quantitative research stage to evaluate which factors to include in the DCE (e.g., Burke et al., 2010). In the present study, the factors included, and levels describing each, were determined by five stages of research using qualitative and quantitative methods.

The first stage involved an extensive analysis of the literature on ECTs, particularly with respect to contributing factors related to teacher attrition and retention. Second, qualitative interviews with 42 teachers confirmed the relevance of these factors in the context of the study and enabled the identification of additional factors (see Buchanan et al., 2013). As a result, an extensive list of factors that impact ECTs' decisions about the attractiveness of their teaching conditions was created. The third stage involved a quantitative research component with 258 ECTs, using best-worst scaling (BWS) to quantify the relative importance and rank of 31 factors as perceived by our participating teachers (Burke et al., 2013). In the fourth stage, a conference organized by the researchers enabled feedback from attendees, which included 29 ECTs and six mentors. Attendees were asked to provide feedback on the extent to which the factors were consistent with the real-world experiences of ECTs. The results gained thus far were then discussed in focus groups at the conference. The participants' insights on these results were collected and used as a further check of the verisimilitude of the findings thus far and of the coherence of the proposed levels for the DCE. In the fifth stage, the findings from the previous research stages were reviewed with representatives of the research sponsor, a state-level government department of education responsible for the employment conditions and provision of support for ECTs. These discussions sought agreement on the specific support factors to include in the DCE based on considering those ranked highest by ECTs as revealed in the BWS stage, and those within the power of the schools and the system to directly address ECTs' preferred 
focus and type of support. On this basis, salary and workload reductions were excluded from the DCE because the research sponsor considered these less amenable to change, given they are determined by government fiscal constraints and through collective bargaining processes (Australian Government Productivity Commission, 2012; Jarimillo, 2012). In total, ten factors were selected for the DCE, each of which relate to teaching conditions critical to the quality of teachers' work (Bascia \& Rottmann, 2011).

The ten factors span the various types of support as outlined in the literature as previously reported, including collegial, executive and mentor support, teaching resources, external resources, and support for professional development. The DCE, however, was also valuable in interrogating the specific nature and focus of support within these general areas that was most attractive to ECTs. To do so, each of the ten factors was further varied in four ways. The selection of these forty levels was validated through further discussions with teacher mentors, beginning teachers and representatives of the research sponsor to confirm that they represented teaching conditions that realistically occur in schools. Once levels for each factor were agreed, further testing was conducted with eight ECTs to ensure each level was adequately described and to ensure their accurate comprehension by respondents. The resulting list of ten factors and associated levels included in the DCE is shown in Table 1.

\section{Insert Table 1 about here}

The factors and associated levels can be combined into a full factorial design consisting of $4^{10}$ combinations, which would require $549,755,289,600$ scenarios if paired comparisons were undertaken. Developments in experimental design theory allow samples to be drawn with 
suitable statistical properties (see Street \& Burgess, 2007). A fractional factorial design approach resulted in 192 choice scenarios consisting of two teaching environments (position A and position B). Each respondent was randomly assigned to one of 24 versions in which they evaluated eight scenarios (see Figure 1).

\section{Insert Figure 1 about here}

For each scenario, respondents indicated their most and least preferred option of the two proposed teaching positions, $\mathrm{A}$ and $\mathrm{B}$, and their current position, and which they preferred out of the two proposed positions. To improve model predictions, respondents were later asked to indicate which description of each factor best matched their current employment situation.

\subsection{Modeling Approach}

The approach used to analyze the data consisted of modeling the choice among teaching positions as a function of the support factors varied in the DCE. The most general model form that researchers use to analyze such data is the conditional logit model (Ben-Akiva \& Lerman, 1985). In this model, respondents are assumed to: a) value each factor in exactly the same way (i.e., hold identical preferences); and, b) make choices using these preferences with the exact same level of error or randomness. However, we used a different approach that relaxes these two assumptions relating to identical preferences and error variability, namely the Scale-Adjusted Latent Class Model (SALCM) developed by Magidson and Vermunt (2007). We now further outline the value in using a model that identifies differences in preferences and error variance 
across a given set of respondents.

Rather than assume all respondents have identical preferences, conventional latent class models are used to identify different latent preference classes. That is, a latent class usually refers to a set of people who hold virtually identical preferences for each and every factor, but differ in their preferences to those in other classes. The identification of a class is latent because its members are unobservable at the time of data collection and inferred from a probabilistic model. The probability that a respondent is a member of a given class is a function of their choice responses and associated preferences. As occurs in this study, membership can be further related to socio-demographic and other characteristics.

A further complication of all discrete choice models arises when respondents differ in the amount of randomness (i.e. error variance) in making their choices. Unfortunately, in most choice models, including general latent class models, the parameter estimates describing preferences are perfectly confounded with the inverse of the error variance (Swait \& Louviere, 1993). Subsequently, when making comparisons of model estimates between groups, it is unclear whether differences between them could be driven by true differences in preference, differences in error variability or both (Swait \& Louviere, 1993). The error variance is inversely related to what is referred to as the scale parameter, which in most choice models is arbitrarily set to unity (Ben-Akiva \& Lerman, 1985, p. 107). Some researchers have developed models which allow the scale parameter to be modeled as a function of various characteristics (e.g., Burke \& Reitzig, 2007; Breffle \& Morley, 2000; Colombo, Hanley, \& Louviere, 2009; Swait \& Adamowicz 2001), but these approaches do not account for differences in preference across latent classes.

Using the SALCM approach, individuals are described as having some probability of being in a particular latent preference class, which distinguishes their preferences for each 
feature level; in addition, simultaneously they are described as having some probability of being in a certain latent scale class, which distinguishes their level of choice consistency from other respondents. The SALCM model has been used in various settings including the study of consumers in response to pesticide use (Glenk, Halla, Liebe, \& Meyerhoff, 2012), the study of decision rules used by respondents in environmental choice experiments (Campbell, Hensher, \& Scarpa, 2011), and studies of museum visitors (Burke et al., 2010). This study is the first reported application of the model in education research. As such, the use of the model in being able to group individuals on the basis of holding similar preferences, whilst accounting for potentially confounding differences in variability, is likely to be attractive to researchers for future research in the field of education research particularly in contexts where identification of distinctive segments is important.

\section{Results}

\subsection{Respondents}

The sample consisted of ECTs defined as those who had begun working within the last three years at a government school located in New South Wales (NSW), the most highly populated state in Australia. Most ECTs teaching in NSW, at the time of the study, were selected for and appointed to their schools through the state government centralized system, managed by the NSW Department of Education and Communities (NSWDEC). In NSW, there are around 49,000 permanent teachers at government schools, with approximately two thirds of school students attending one of the 2,200 government schools (NSW Government, 2011). At the time of the study, in NSW there were approximately 760,000 students (NSWDEC, 2014) with around $30 \%$ being those from non-English speaking backgrounds and six percent being Aboriginal 
(NSW Government, 2012). Close to three percent of students receive special education, support in an integrated setting, or attend a specialized school.

In Australia, teaching standards outline the expectations of teachers at different levels: graduate, proficient, accomplished, and lead (see AITSL, 2014). The standards are similar to those in other English speaking countries, although there is variation in their application (Schuck et al., 2012). At the time of the study, as graduates were from approved university teacher education courses, ECTs had met the graduate standards. Those employed as full-time permanent teachers by NSWDEC were required to demonstrate achievement at the proficient level within one year. Teachers in casual or temporary positions had up to five years to meet this level.

In NSWDEC schools, a teacher is responsible for supporting ECTs in preparing evidence of their achievement of the standards for submission to an accrediting authority. ECTs who do not meet the required standards risk losing their continuing employment status. Each full time ECT is assigned a mentor and each school has its own induction program for ECTs. In addition, the NSWDEC provides a number of online resources and training programs to assist various teachers in their employment and teaching.

All 2,500 qualifying ECTs listed on the database provided by the research partner were sent an email invitation and a follow-up reminder to complete the survey, from which 336 complete responses were obtained (a response rate of 13\%). As DCEs elicit multiple evaluations from each respondent, this was more than adequate to estimate the model, to identify latent segments within the data, and detect significant differences in relation to their preferences among support features and decision variability (Louviere et al., 2000). Respondents were predominantly female (77\%), a figure consistent with the high proportion of females currently teaching in NSW. The majority were in full-time employment (94\%), with four percent 
employed part-time, whilst two percent had left the profession. Forty per cent were teaching in primary schools, $50 \%$ in secondary schools, and 5\% were at schools with both primary and secondary students. While $82 \%$ were teaching in schools that were located in a large city, $18 \%$ were teachers at a school located in a rural area. Respondents consisted of those teaching across all secondary key learning areas, and all primary years. Sixty-four per cent of respondents were under the age of $30,19 \%$ in their 30 s, and the remaining $17 \%$ were 40 or older. The highest qualification for the majority of respondents was a Bachelor degree (68\%), while $18 \%$ had a graduate diploma, and $11 \%$ held a Masters or $\mathrm{PhD}$. Almost all respondents had access to the internet at home (94\%). Several respondents were currently undertaking further study (16\%), of whom a quarter were pursuing postgraduate studies in an area outside education.

\subsection{Actual experience of ECTs}

Teachers also described their current practices and workplace conditions in their school. To improve model predictions, the data from these questions were used in the choice model to define the current experiences of each teacher for each variable rather than assume each of their current teaching conditions were identical. The results provide interesting insights (see Table 2). For example, close to half (47\%) reported working in an isolated environment with little collaboration, whilst a quarter $(26 \%)$ reported having limited professional conversations about teaching practice. Only $14 \%$ of respondents reported having no professional development support to achieve mandatory professional teaching standards.

Insert Table 2 about here 
Respondents were asked to indicate their plans in terms of teaching in the next 12 months and to indicate whether they planned to remain in the profession or not. Close to $75 \%$ stated an intention to remain in the profession in the next 12 months, and we refer to these as 'stayers'. The remaining set of ECTs, with a stated intention to leave the profession in the next 12 months, we refer to as 'leavers'. The focus of this study is on the valuation of support mechanisms for ECTS to maximize retention in the teaching profession, so our use of the term 'stayers' includes both those with the intention to remain in their current position and those who intend to move (i.e., migrators) within the profession (Ingersoll \& May, 2012). Explaining departure intentions, among the $24 \%$ of ECTs surveyed who were considering leaving the profession, $55 \%$ cited reasons associated with their current employment situation, whilst only $16 \%$ cited their intentions to leave were due to family reasons. The final column in Table 2 indicates whether experiences across these two groups are significantly different.

ECTs who expressed intentions to leave appear to be those who are more likely to experience: a) little sharing of resources and less ICT support; b) limited opportunities to work with experienced teachers, particularly in relation to cooperative planning activities; c) a lack of planned professional conversations, particularly with supervisors; and, d) limited mentor access.

\subsection{SALCM Results}

A DCE and associated choice model (SALCM) were developed to predict what conditions of support for ECTs is preferable using the LatentGOLD software developed by Magidson and Vermunt (2007). The first component of the SALCM estimates identified two underlying scale classes. One scale class represents around $75 \%$ of respondents, and its members are more likely to be females with a Masters or $\mathrm{PhD}$ qualification, planning to remain in the 
profession, who encounter significant time commitments in assisting students with a disability (see Table 3). The other scale class represents around $25 \%$ of respondents, and predicted to be those ECTs who are more likely to leave the profession, be male, with a graduate diploma, and are less likely to encounter students with learning difficulties. All other differences in teacher or school related factors were not significant in predicting which ECTs were more likely to be identified in either of the two scale classes or, as explained later, the two identified preference classes. If these differences in choice variability were not accounted for, the description of the latent preference classes would be based on biased estimates and therefore misleading (Campbell et al., 2011).

\section{Insert Table 3 about here}

The model identified two latent classes that are distinguished by their preferences for different optimal working conditions (see Table 3). The larger segment consists of approximately $67 \%$ of respondents and we label these teachers 'stayers'. Teachers in this latent preference class are more likely to be those who plan to remain in the profession, who face higher demands associated with managing students with learning difficulties, and who have more advanced levels of tertiary qualifications (Masters or $\mathrm{PhD}$ ). The smaller segment, making up 33\% of respondents, we label 'leavers'. Teachers in this latent preference class are more likely to be those ECTs who reported that they plan to leave the profession, hold a Graduate Diploma or Bachelor Degree, and have fewer time demands associated with managing students with learning difficulties.

The parameter estimates reported in Table 4 capture the preference for any one aspect of supporting ECTs relative to other strategies that could be realized in the teaching conditions for 
the two latent preference classes, 'stayers' and 'leavers'; the final column reports whether such differences are significant. For example, the results indicate that 'stayers' are indifferent with respect to the three forms of affirmation and inclusion that refer to professional recognition, professional voice, and executive interest. However, 'stayers' significantly prefer any of these forms of recognition compared to positions where affirmation involves the recognition of personal milestones (e.g., birthdays). On the other hand, 'leavers' express a significant preference for having a voice in the professional activities of the school (e.g., at staff meetings), however, similarly they express a preference for the other forms of recognition presented compared to those that recognize personal milestones.

\section{Insert Table 4 about here}

A summary of the results presented in Table 4 suggests that those planning to stay in the profession have a significant preference for resource sharing (particularly through electronic means); working with more experienced teachers through cooperative planning and observation; having planned conversations about teaching with other ECTs or with supervisors; meeting with their mentor at their school, with discussions focused on classroom management rather than managing stakeholders (e.g., parents); preference for government-sponsored resources to focus on curriculum matters rather than focused on legal matters or accessed via videoconferencing; and, attending workshops or conferences for professional development relative to such activities that take place at the school or online.

Whilst those expressing an intention to leave the profession hold similar preferences to those intending to remain in relation to some elements of support (e.g. types of teaching 
resources), the differences are significant in many regards. In summary, ECTs categorized as 'leavers' hold a significant preference for: a professional voice as opposed to receiving affirmation and inclusion in the form of personal milestones being recognized; the sharing of resources, largely favoring electronic forms; off-campus access to a teaching mentor; mentor discussions to be about classroom management, programming and assessment, with a preference not to discuss matters of career planning; availability of government-based resources online, and for these to be focused on matters of teaching and learning, as opposed to legal matters; and, release for development activities that occur in the form of in-school collegial professional support.

The analysis of current positions and the DCE data allowed exploration of the possible different segments that exist in the data and highlighted the need to consider how aggregate statistics can offer a biased insight into what is occurring among different sets of individuals. For example, whilst around $30 \%$ of ECTs reported no genuine sharing of teaching resources within their school, this figure was much higher (around 45\%) in the case of those who have intentions to leave the profession. In addition, the SALCM offered further advantages in not only identifying underlying latent segments in the data that differ with respect to their preferences among factors, but also simultaneously accounted for issues relating to biases introduced by differences in underlying variability across individuals. The implications of these results are now considered in greater detail with respect to addressing substantive and practical questions about preferences among ECTs for variation in the types of support that may be offered to them.

\section{Discussion}

The purpose of this study was to examine ECTs' relative preference for different types of 
support and account for how such preferences vary among ECTs. The proportion of ECTs stating their intention to leave the profession in the next 12 months was close to $25 \%$, a figure that further supports the broad concerns about ECT retention rates that have been previously identified in the literature. As previously noted with respect to Table 2, whilst all ECTs surveyed experience forms of isolation and limited access to resources, this issue appears to be more pronounced among 'leavers', those with intentions to leave the profession, relative to 'stayers', those with intentions to remain in the profession. 'Leavers' currently experience a more pronounced lack of sharing with respect to teaching resources, higher levels of isolation in terms of working with more experienced teachers, and a lack of interaction in terms of holding planned conversations about their teaching including those with their assigned mentors. Differences in preferences for optimal working conditions identified via the SALCM were largely associated with differences in teachers' stated intentions to remain or leave the profession. We now discuss the strategic insights arising from the predictive model about how best to approach questions of developing a supportive environment that is attractive to both 'stayers' and 'leavers'.

\subsection{Resources}

The sharing of resources and collective cooperation among staff has been linked to retention among ECTs (e.g., Allensworth et al., 2009; Boyd et al., 2011). In the current study, almost a third of ECTs report a lack of sharing in their current teaching environments. Among 'leavers' this figure is more concerning with $45 \%$ reporting no genuine sharing of teaching resources. With respect to preferences regarding teaching resources, the types of support valued are similar for both those with intentions to leave the profession and those with intentions to remain. Specifically, both segments are averse to those workplace environments where teachers 
keep resources to themselves, whereas initiatives that encourage sharing of resources (electronic or offline via a common storage place) are valued. This suggests schools would benefit from understanding ways to change attitudes among teachers about sharing or to investigate the incentives for doing so. Existing infrastructure at schools may not always exist to promote sharing and collaboration, and this has been identified as a broad concern for the teaching profession (Killeavy \& Moloney, 2010). Nevertheless, there has been some success in the use of rewards in the establishment of online repositories (Koppi, Bogle, \& Bogle, 2005). The encouragement of sharing and of reducing competitiveness for resources may fall upon principals in their endeavors to create organizational norms where collective goals of improvement in student learning and alignment of beliefs in teaching occur (Jones et al., 2013).

ECTs value and aspire to the expertise and resource capabilities encapsulated by their more experienced colleagues (Allen, 2009). Our results indicate that 'stayers' currently experience larger levels of resource sharing, with the main form of sharing occurring through physical mediums, such as through a pigeon hole or "common drawer" with communal access among teachers. However, the findings from the DCE indicate that the preferred mode of sharing was through electronic access including online access at home. Whilst this may have been a prohibitive form of access in the past, $94 \%$ of ECTs surveyed had internet access at home. Ways of establishing electronic sharing, such as resource repositories within schools, could be explored in order to address this need. One advantage of a school-based resource over a state, national or international resource, may be that the content is contextualized for the students that the individual ECT is teaching.

\subsection{Working with colleagues}


Almost half of ECTs reported isolation with respect to working with more experienced teachers. If ECTs did have opportunities to work with more experienced teachers, the majority of these interactions involved co-planning activities rather than activities such as co-teaching or collaborative observation. However, the DCE results provide strong indications that both 'stayers' and 'leavers' seek to minimize isolation in planning and development activities. While the two sets of ECTs differ in their perceptions about how to work with more experienced teachers, both favor cooperative planning for teaching and learning (e.g., lesson preparation, assessment design). This finding suggests that opportunities need to be continued for ECTs to collaborate with colleagues in planning and preparation, which is consistent with literature on contributing factors to ECT retention (e.g., Abdallah, 2009; Boyd et al., 2011) and on other positive outcomes, such as improvements in teacher efficacy (e.g., Devos, Dupriez, \& Paquay, 2012). Our findings show that the need for collaboration is particularly relevant for those with intentions of leaving the profession, with the majority reporting that they have no opportunities to work with experienced teachers, with $63 \%$ reporting isolation in this regard. The role of administrators and their encouragement of positive staff relations are important with respect to retention among ECTs (Boyd et al., 2011). To enable greater collaboration, ways of reducing face-to-face teaching time may require consideration; this could have implications for resourcing, distribution of workload or class sizes. Changes such as these, however, are subject to financial and industrial constraints and the potential impact on ECTs and students is uncertain (Bascia \& Rottmann, 2011; Hall \& Nuttall, 1999).

\subsection{Support from Mentors}

Previous literature has established a link between mentoring and retention (e.g., Ingersoll 
\& Strong, 2011; Odell \& Ferraro, 1992; Smith \& Ingersoll, 2004). However, the current research highlights how responses to introduced supportive initiatives may differ between those with intentions to remain in the profession and those with intentions to leave. The largest difference between 'stayers' and 'leavers' is associated with the medium by which ECTs interact with their assigned mentor. 'Stayers' view the medium of interaction with mentors as being attractive only when meeting in person at their own school, and dislike interactions online. This is largely reflective of the current experience of these ECTs, with 92\% meeting with their assigned mentor at their school. Similarly, $87 \%$ of those stating an intention to leave the profession have meetings with their mentors at their school. However, the results from the DCE reveal that 'leavers' would prefer not to meet with their mentor at the school at which they teach, and are indifferent to other ways of interacting with their mentor. 'Leavers' may not value the meetings they currently have with their mentors. Mentors for the teachers in this study are not chosen by ECTs but assigned. Interestingly, these same 'leavers' value working with more experienced teachers through cooperative planning and co-teaching. In terms of professional development activities, they favor in-school collegial professional support. This suggests that the preference for meeting outside of school may be a function of the particular relationship that they have with their current schoolbased mentor rather than the location per se. This may also explain why 'leavers' have no interest in having career planning discussions with their mentor.

\subsection{Planning and development activities}

'Leavers' appear to favor professional support that focusses on their immediate needs for classroom teaching (cooperative planning; co-teaching). 'Stayers' were also interested in professional development activities in which they could attend workshops or conferences, and 
expected to invest in such activities that underpin their long-term professional development. Potentially, this can be thought of in terms of the level of construal that teachers associate with their discussions and decisions about teaching. Construal level theory (Trope \& Liberman, 2010) distinguishes between the psychological distance that people associate with an object or an event, and whether resulting thoughts about the same object occur in an abstract or concrete manner. In construal theory, people may be future orientated or present orientated: it is likely that 'leavers' would be more present orientated, and prefer planning for actual teaching lessons rather than engaging in broad conversations about teaching and learning that 'stayers' value more. Viewed in this way, 'stayers' may be more willing to engage in questions about teaching and learning in a more abstract manner that might underpin their long term teaching capability. In contrast, 'leavers' may be more concerned about the immediate and everyday specific demands of their teaching.

Similarities in preference across the majority of ECTs for some types of support were observed. For example, all ECTs expressed a desire for greater levels of support in classroom management, which is consistent with other findings in the literature (e.g., Brouwers \& Tomic, 2000). This supports the current trend in increasing the expertise of ECTs in classroom management through initial teacher education and in ongoing professional learning (e.g., Basit et al., 2006; Rudducka, 1991).

\subsection{School climate and professional voice}

In their current circumstances, 'stayers' and 'leavers' have a similar level of professional voice in their schools. Menon and Athanasoula-Reppa (2011) suggest that attrition is related to a lack of participation in management experienced by teachers. This is consistent with the current 
findings in which 'leavers' expressed a preference for settings in which they had a professional voice (e.g., in staff meetings or through committees). Such inclusion can improve the quality of administrator-teacher relations, which has been shown to be a strong predictor of retention among ECTs (e.g., Pogodzinski et al., 2012). However, our findings suggested that those with intentions to remain in the profession were indifferent to such inclusion. In this regard, furthering opportunities for professional voice appears unlikely to have an impact on 'stayers', but could contribute to creating perceptions of a healthy administrative climate attractive to some ECTs who would otherwise leave the profession.

\subsection{Limitations and Future Research}

In this research, the use of a choice model was based on a DCE, a form of data collection that generates stated preference data. Hence, there are some limitations in regard to establishing external validity relative to methods that rely on revealed preference data that are observable in real settings. Empirically, however, model comparisons suggest that data collected in DCEs are often strongly linked to what occurs in real settings (e.g. Earnhart, 2002). Data from real settings are often complicated by the co-occurrence of some factors leading to higher rates of multicollinearity, which creates biases in model estimation (Street \& Burgess, 2007). The DCE approach also presented the opportunity to see how ECTs would respond to certain support strategies that may not be currently available to them, but for which they could indicate their preference or dissatisfaction.

There is a need to consider the need for future research in other settings outside of the Australian context. Whilst the experience of Australian ECTs share similarities with respect to their training, induction and remuneration relative to teachers in other countries, particularly 
those in Western settings, accounting for variation in respective teaching environments would be useful in better understanding differing preferences for support.

Our categorization of respondents into 'stayers' and 'leavers' was based on ECTs' projected intentions to remain or stay in the profession over the next 12 months, not actual departure behavior. Nonetheless, the finding that $25 \%$ of ECTs had plans to depart from the profession highlights the problem of beginning teacher attrition as a substantial issue. Whilst, Henry, Bastian, and Fortner (2011) present evidence to suggest that those ECTs leaving the profession are less effective, they do suggest that ways to improve effectiveness (e.g., through induction) are required. In general, finding better ways to support better teaching amongst ECTs should not be driven by motivations to address issues of retention. Rather support should improve the experience of ECTs so that it enhances teacher efficacy and their capacity to contribute to their students' learning (Bascia \& Rottmann, 2011). One avenue for future research is to explore the ways in which different types of support may strengthen a range of broader outcomes such as teaching quality.

A final consideration in evaluating the findings is that there was no distinction made among the segment we labeled 'stayers' in terms of whether they were planning to remain in the profession in their current position or were planning to migrate to a position at another school. As reported earlier, similar limitations have been noted in other studies of retention, in which it is not clear whether those leaving the school comprise only those teachers moving to another school, or also include those teachers leaving the profession entirely (e.g., Allensworth et al., 2009; Ingersoll \& May, 2012). Consequently, it may be worthwhile for future research to consider distinctions in preference for support between at least these three sub-groups: those teachers remaining at a particular school, those taking a position at another school, and those 
leaving the profession entirely.

\section{Conclusion}

The research highlights the role that other teachers have in creating positive experiences for ECTs, whether through mentoring, co-planning or professional conversations. The establishment of formal mentoring programs continues to dominate policy discussion and receive widespread adoption. This study contributes additional insights regarding collaboration and resources. It highlights the role of principal leadership in establishing organizational climates that are conducive to supporting ECTs, including those that positively shape beginning teachers' perceptions regarding their fit within the school community.

By quantifying what ECTs value in terms of the format, focus and delivery of support mechanisms, the study offers clear directions for executive and school staff on how to support ECTs in ways that fit best with their preferences. A key outcome of the research is that ECTs with intentions to leave the profession relative to those with intentions to stay hold differing preferences for how they wish to be supported. ECTs with intentions to depart the profession, place greater relative value on the sharing of resources, cooperative teaching and planning, offsite discussions about classroom management and programming with mentors, and having a greater professional voice. In contrast, those with intentions to remain, place greater value on observation from and conversations about teaching with more experienced teachers at their school.

If resources for support are limited, policy makers and school leaders need to determine which of these groups should be targeted and recognize that a strategy designed to support one group may be ineffective or negatively impact on the other. However, both sets of ECTs would 
welcome opportunities to promote and encourage wider forms of formal and informal collaboration and exchange of resources with their colleagues.

\section{Acknowledgements}

This project was financially supported by the New South Wales Department of Education and Training (NSWDET), now named the NSW Department of Education and Communities (NSWDEC). 


\section{References}

Abdallah, J. (2009). Lowering teacher attrition rates through collegiality. Academic Leadership Journal, 7(1), 7-8.

Alhija, F. N. \& Fresko, B. (2010). Socialization of new teachers: Does induction matter? Teaching and Teacher Education, 26(8), 1592-1597.

Allen, J. M. (2009). Valuing practice over theory: How beginning teachers re-orient their practice in the transition from the university to the workplace. Teaching and Teacher Education, 25(5), 647-654.

Allensworth, E., Ponisciac, S., \& Mazzeo, C. (2009). The schools teachers leave: Teacher mobility in Chicago Public Schools. Chicago: Consortium on Chicago School Research.

Australian Government Productivity Commission. (2012). Schools workforce: Productivity Commission research report. Canberra: Australian Government. Retrieved from: http://www.pc.gov.au/_data/assets/pdf_file/0020/116651/schools-workforce.pdf

Australian Institute for Teaching and School Leadership (AITSL). (2014). Australian Professional Standards for Teachers. Retrieved from: http://www.aitsl.edu.au/australian-professional-standards-for-teachers/standards/list

Bascia, N., \& Rottmann, C. (2011). What's so important about teachers' working conditions? The fatal flaw in North American educational reform. Journal of Education Policy, 26(6), 787-802.

Basit, T. N., Roberts, L., McNamara, O., Carrington, B., Maguire, M., \& Woodrow, D. (2006). Did they jump or were they pushed? Reasons why minority ethnic trainees withdraw from initial teacher training courses. British Educational Research Journal, 32(3), 387410. 
Baumgartner, H., \& Steenkamp, J.E.M. (2001). Response Styles in Marketing Research: A Cross-national Investigation. Journal of Marketing Research 38(2): 143-156.

Ben-Akiva, M., \& Lerman, S. R. (1985). Discrete choice analysis: Theory and application to predict travel demand. Cambridge, MA: The MIT press.

Bickmore, D. \& Bickmore, S. (2010). A multifaceted approach to teacher induction. Teaching and Teacher Education, 26(4), 1006-1014.

Borman, G. D., \& Dowling, N. M. (2008). Teacher attrition and retention: A meta-analytic and narrative review of the research. Review of Educational Research, 78(3), 367-409.

Boyd, D., Grossman, P., Ing, M., Lankford, H., Loeb, S., \& Wyckoff, J. (2011). The influence of school administrators on teacher retention decisions. American Education Research Journal, 48(2), 303-333.

Buchanan, J., Prescott, A., Schuck, S., Aubusson, P., Burke, P., \& Louviere, J. (2013). Teacher retention and attrition: views of early career teachers. Australian Journal of Teacher Education, 38(3), 112-129.

Burke, P. F., Burton, C., Huybers, T., Islam, T., Louviere, J. J., \& Wise, C. (2010). The scaleadjusted latent class model: application to museum visitation. Tourism Analysis, 15(2), 147-165.

Burke, P. F., \& Reitzig, M. (2007). Measuring patent assessment quality-analyzing the degree and kind of (in) consistency in patent offices' decision making. Research Policy, 36(9), 1404-1430.

Burke, P. F., Schuck, S., Aubusson, P., Buchanan, J., Louviere, J. J., \& Prescott, A. (2013). Why do early career teachers choose to remain in the profession? The use of best-worst scaling to quantify key factors. International Journal of Educational Research, 62, 259-268. 
Breffle, W. S., \& Morey, E. R. (2000). Investigating preference heterogeneity in a repeated discrete-choice recreation demand model of Atlantic salmon fishing. Marine Resource Economics, 15(1), 1-20.

Brouwers, A., \& Tomic, W. (2000). A longitudinal study of teacher burnout and perceived selfefficacy in classroom management. Teaching and Teacher Education, 16(2), 239-253.

Campbell, D., Hensher, D. A., \& Scarpa, R. (2011). Non-attendance to attributes in environmental choice analysis: a latent class specification. Journal of Environmental Planning and Management, 54(8), 1061-1076.

Caspersen, J. \& Raaen, F. (2014). Novice teachers and how they cope. Teachers and Teaching, 20(2), 189-211.

Chan, W., Lau, S., Nie, Y., Lim, S., \& Hogan, D. (2008). Organizational and personal predictors of teacher commitment: The mediating role of teacher efficacy and identification with school. American Journal of Educational Research, 45(3), 597-630.

Colombo, S., Hanley, N., \& Louviere, J. (2009). Modeling preference heterogeneity in stated choice data: an analysis for public goods generated by agriculture. Agricultural Economics, 40(3), 307-322.

Corbell, K. A., Reiman, A. J., \& Nietfeld, J. L. (2008). The perceptions of success inventory for beginning teachers: Measuring its psychometric properties. Teaching and Teacher Education, 24(6), 1551-1563.

Darling-Hammond, L. (2006). Securing the right to learn: Policy and practice for powerful teaching and learning. Educational Researcher, 35(7), 13-24.

Devos, C., Dupriez, V., \& Paquay, L. (2012). Does the social working environment predict beginning teachers' self-efficacy and feelings of depression? Teaching and Teacher 
Education, 28(2), 206-217.

Earnhart, D. (2002). Combining revealed and stated data to examine housing decisions using discrete choice analysis. Journal of Urban Economics, 51(1), 143-169.

Ewing, R., \& Smith, D. (2003). Retaining quality beginning teachers in the profession. English Teaching: Practice and Critique, 2(1), 15-32.

Fantilli, R.D. \& McDougall, D.E. (2009). A study of novice teachers: Challenges and supports in the first years. Teaching and Teacher Education, 25(6), 814-825.

Fenwick, A., \& Weir, D. (2010). The impact of disrupted and disjointed early professional development on beginning teachers. Teacher Development, 14(4), 501-517.

Garet, M., Porter, A., Desimone, L., Birman, B., \& Yoon, K. (2001). What makes professional development effective? Results from a national sample or teachers. American Educational Research Journal, 38(4), 915-945

Glenk, K., Hall, C., Liebe, U., \& Meyerhoff, J. (2012). Preferences of Scotch malt whisky consumers for changes in pesticide use and origin of barley. Food Policy, 37(6), 719731.Guarino, C. M., Santibanez, L., \& Daley, G. A. (2006). Teacher recruitment and retention: A review of the recent empirical literature. Review of Educational Research, 76(2), 173-208.

Hall, K., \& Nuttall, W. (1999). The relative importance of class size to infant teachers in England. British Educational Research Journal, 25(2), 245-258.

Harrison, J., Dymoke, S., \& Pell, T. (2006). Mentoring beginning teachers in secondary schools: An analysis of practice. Teaching and Teacher Education, 22(8), 1055-1067.

Henry, G. T., Bastian, K. C., \& Fortner, C. K. (2011). Stayers and leavers: Early-career teacher effectiveness and attrition. Educational Researcher, 40(6), 271-280. 
Henry, G. T., Bastian, K. C., \& Smith, A. A. (2012). Scholarships to recruit the "Best and Brightest" into teaching: Who is recruited, where do they teach, how effective are they, and how long do they stay? Educational Researcher, 41(3), 83-92.

Hess, S., \& Daly, A. (Eds.). (2013). Choice modelling: The state of the art and the state of practice. Cheltenham, UK: Edward Elgar Publishing.

Hong, J. Y. (2010). Pre-service and beginning teachers' professional identity and its relation to dropping out of the profession. Teaching and Teacher Education, 26(8), 1530-1543.

House of Commons Education Committee. (2012). Great teachers: Attracting, training and retaining the best: Ninth Report of Session 2010-12, Volume I: Report, together with formal minutes. London: The Stationary Office Ltd,. Retrieved from: http://www.publications.parliament.uk/pa/cm201012/cmselect/cmeduc/1515/1515.pdf

House of Representatives Standing Committee on Education and Vocational Training (2007). Top of the class: Report on the inquiry into teacher education. Canberra: House of Representatives Publishing Unit. Retrieved from: http://www.aph.gov.au/parliamentary_business/committees/house_of_representatives_co $\underline{\text { mmittees?url=evt/teachereduc/report.htm }}$

Hutchison, A. \& Colwell, J. (2012). Using a wiki to facilitate an online professional learning community for induction and mentoring teachers. Education and Information Technologies, 17(3), 273-289.

Ingersoll, R. M., \& May, H. (2012). The magnitude, destinations, and determinants of mathematics and science teacher turnover. Educational Evaluation and Policy Analysis, $34(4), 435-464$.

Ingersoll, R. M., \& Strong, M. (2011). The impact of induction and mentoring programs for 
beginning teachers: A critical review of the research. Review of Educational Research, $81(2), 201-233$.

Islam, T., Louviere, J. J., \& Burke, P. F. (2007). Modeling the effects of including/excluding attributes in choice experiments on systematic and random components. International Journal of Research in Marketing, 24(4), 289-300.

Jones, N., Youngs, P., \& Frank, K. (2013). The role of school-based colleagues in shaping the commitment of novice special and general education teachers. Exceptional Children, 79(3), 365-383.

Jaramillo, M. (2012). The spatial geography of teacher labor markets: Evidence from a developing country. Economics of Education Review, 31(6), 984-995.

Jarzabowski, L. (2003). Teacher collegiality in a remote Australian school. Journal of Research in Rural Education, 18(3), 139-144.

Johnson, S. M. (2007). Finders and keepers: Helping new teachers survive and thrive in our schools. Indianapolis, IN: Jossey-Bass.

Johnson, S. M., J. H. Berg, \& Donaldson, M. L. (2005). Who stays in teaching and why?: A review of the literature on teacher retention. Harvard Graduate School of Education: Project on the Next Generation of Teachers. Retrieved from: http://assets.aarp.org/www.aarp.org_/articles/NRTA/Harvard_report.pdf

Kapadia, K. Coca, V. \& Easton, J. Q. (2007). Keeping new teachers: A first look at influences of induction in the Chicago Public Schools. Chicago: Consortium on Chicago School Research, University of Chicago

Killeavy, M., \& Moloney, A. (2010). Reflection in a social space: Can blogging support reflective practice for beginning teachers? Teaching and Teacher Education, 26(4), 1070- 
1076.

Kirby, S. N., Berends, M., \& Naftel, S. (1999). Supply and demand of minority teachers in Texas: Problems and prospects. Educational Evaluation and Policy Analysis, 21(1), 4766.

Klassen, R. M., \& Anderson, C. J. (2009). How times change: secondary teachers' job satisfaction and dissatisfaction in 1962 and 2007. British Educational Research Journal, 35(5), 745-759.

Koppi, T., Bogle, L., \& Bogle, M. (2005). Learning objects, repositories, sharing and reusability. Open Learning: The Journal of Open, Distance and e-Learning, 20(1), 83-91.

Ladd, H. (2011). Teachers' perceptions of their working conditions: How predictive of planned and actual teacher movement? Educational Evaluation and Policy Analysis, 33(2), 235261.

Le Maistre, C., \& Paré, A. (2010). Whatever it takes: How beginning teachers learn to survive. Teaching and Teacher Education, 26(3), 559-564.

Löfström, E. \& Eisenschmidt, E. (2009). Novice teachers' perspectives on mentoring: The case of the Estonian induction year. Teaching and Teacher Education, 25(5), 681-689.

Liu, S., \& Onwuegbuzie, A. J. (2012). Chinese teachers' work stress and their turnover intention. International Journal of Educational Research, 53, 160-170.

Louviere, J. J., Hensher, D. A., \& Swait, J. D. (2000). Stated choice methods: analysis and applications. Cambridge University Press.

Louviere, J. J., \& Islam, T. (2008). A comparison of importance weights and willingness-to-pay measures derived from choice-based conjoint, constant sum scales and best-worst scaling. Journal of Business Research, 61(9), 903-911. 
Lukens, M. T., D. M. Lyter, \& Fox, E. E. (2004). Teacher attrition and mobility: Results from the teacher follow-up survey, 2000-01. Washington, DC: National Center for Educational Statistics, U.S. Department of Education.

Magidson, J. \& Vermunt, K.J. (2007). Removing the scale factor confound in multinomial logit choice models to obtain better estimates of preference. Paper presented at 2007 Sawtooth Symposium, Santa Rosa, California, October 15-19. Retrieved from: http://statisticalinnovations.com/technicalsupport/sawtooth2007.pdf

Mayer, D. (2006). The changing face of the Australian teaching profession: New generations and new ways of working and learning. Asia-Pacific Journal of Teacher Education, 34(1), $57-71$.

Menon, M. E., \& Athanasoula-Reppa, A. (2011). Job satisfaction among secondary school teachers: The role of gender and experience. School Leadership \& Management, 31(5), 435-450.

NSW Council of Deans of Education (NSW CDE). (2012). Response To 'Great Teaching, Inspired Learning'. Sydney: NSW Government Discussion Paper. Retrieved from: http://www.nswcde.org.au/content/download/87/383/file/NSWCDE\%20discussion\%20pa per\%20response\%20draft\%2031Oct2012.pdf

NSW DEC. (2013). 2013 Teaching Workforce Supply and Demand: School Teachers in NSW Public Schools. Sydney: NSW Department of Education \& Communities (NSWDEC). Retrieved from: https://www.det.nsw.edu.au/media/downloads/about-us/statistics-andresearch/key-statistics-and-reports/workforce-plan-4-school-teachers.pdf

NSW DEC. (2014). NSW Public Schools February census enrolment data, NSW Department of Education \& Communities (NSWDEC). Retrieved from: 
https://www.det.nsw.edu.au/media/downloads/about-us/statistics-and-research/keystatistics-and-reports/enrolments-feb14.pdf

NSW Government (2011) Submission to the Productivity Commission's Education and Training Workforce Study: Schools. Retrieved from: http://www.pc.gov.au/_ data/assets/pdf file/0016/111652/sub014.pdf

NSW Government. (2012). Budget Estimates 2012-2013: Paper 3, Education and Communities Cluster, New South Wales Treasury, Retrieved from: http://www.treasury.nsw.gov.au/_data/assets/pdf_file/0006/24639/bp3_03educ_and_co $\underline{\text { mm.pdf }}$

Odell, S. J., \& Ferraro, D. P. (1992). Teacher mentoring and teacher retention. Journal of Teacher Education, 43(3), 200-204.

OECD. (2005). Teachers Matter: Attracting, Developing and Retaining Effective Teachers. OECD Publishing. Retrieved from: http://www.oecd.org/edu/school/attractingdevelopingandretainingeffectiveteachersfinalreportteachersmatter.htm

Pogodzinski, B., Youngs, P., Frank, K., \& Belman, D. (2012). Administrative climate and novices' intent to remain teaching. The Elementary School Journal, 113(2), 252-275.

QCT (2013). Attrition of Recent Queensland Graduate Teachers, Report by Queensland College of Teachers (QCT), November, 2013. Retrieved from: http://www.qct.edu.au/Publications/Retention_Research_Report_RP01.pdf

Rudducka, J. (1991). The language of consciousness and the landscape of action: Tensions in teacher education. British Educational Research Journal, 17(4), 319-331.

Schuck, S. (2003). Getting help from the outside: developing a support network for beginning 
teachers. Journal of Educational Enquiry, 4(1), 49-67.

Schuck, S.R., Aubusson, P.J., Buchanan, J.D. \& Russell, T. (2012). Beginning Teaching: Stories from the classroom. Dordrecht, The Netherlands: Springer.

Smith, T. \& Ingersoll, R. (2004). What are the effects of induction and mentoring on beginning teacher turnover? American Educational Research Journal, 41(3), 681-714.

Stinebrickner, T. R. (1998). An empirical investigation of teacher attrition. Economics of Education Review, 17(2), 127-136.

Stormont, M., Reinke, W., \& Herman, K. (2011). Teachers' knowledge of evidence-based interventions and available school resources for children with emotional and behavioral problems. Journal of Behavioral Education, 20(2), 138-147.

Street, D., \& Burgess, L. B. (2007). The construction of optimal stated choice experiments: Theory and methods. Hoboken, NJ: John Wiley and Sons.

Swait, J., \& Adamowicz, W. (2001). Choice environment, market complexity, and consumer behavior: A theoretical and empirical approach for incorporating decision complexity into models of consumer choice. Organizational Behavior and Human Decision Processes, 86(2), 141-167.

Swait, J., \& Louviere, J. (1993). The role of the scale parameter in the estimation and comparison of multinomial logit models. Journal of Marketing Research, 30(3), 305-314.

Tickle, B., Chang, M., \& Kim, S. (2011). Administrative support and its mediating effect on US public school teachers. Teaching and Teacher Education, 27(2), 342-349.

Trope, Y., \& Liberman, N. (2010). Construal-level theory of psychological distance. Psychological Review, 117(2), 440.

Tytler, R., Smith, R., Grover, P., \& Brown, S. (1999). A comparison of professional 
development models for teachers of primary mathematics and science. Asia-Pacific Journal of Teacher Education, 27(3), 193-214.

Weiss, E. M. (1999). Perceived workplace conditions and first-year teachers' morale, career choice commitment, and planned retention: A secondary analysis. Teaching and Teacher Education, 15(8), 861-879. 


\section{Indication of Figures and Tables:}

Table 1: Factors and Corresponding Factor Levels Included in DCE

Table 2: Actual Experience of ECTs in Schools in relation to existing support

Table 3: Predicted Latent Preference and Scale (Variance) Class Membership

Table 4: Parameter Estimates for ECT Factors: Preference by Class

Figure 1: Example of a Choice Scenario 
Table 1: Factors and Corresponding Factor Levels Included in DCE

\section{Factor 1: AFFIRMATION AND INCLUSION}

1. Recognition (eg via emails; announcements) of personal milestones (eg birthdays)

2. Recognition (eg via emails; announcements) of activities/achievements in and outside of class (eg excursions; accreditation progress)

3. Voice in professional activities of school (eg at staff meetings; inclusion in committees)

4. Greeting and enquiries from executive staff about how you're going (interest shown)

\section{Factor 2: TEACHING RESOURCES}

1. Pigeon hole or "common drawer" allowing shared access to other teachers' and/or school resources/materials

2. Electronic access to teaching resources (including access at home online)

3. Support for the use of computers in classrooms and in teaching and learning programs

4. Each teacher keeps school developed resources to themselves (no genuine sharing)

Factor 3: WORKING WITH MORE EXPERIENCED TEACHERS

1. Cooperative planning for teaching and learning (Lesson preparation, design of teaching \& assessment tasks)

2. Co-planning and co-teaching/team teaching a class together

3. Working together collaboratively with experienced teacher by observing and being observed in classroom

4. Little collaboration - work in isolation in planning and developing of teaching and learning activities

Factor 4: PLANNED PROFESSIONAL CONVERSATIONS ABOUT TEACHING PRACTICE

1. With other beginning teachers at my school or at other schools in similar roles, subjects or stages

2. With my supervisor

3. With my mentor

4. Limited professional conversations about teaching practice

\section{Factor 5: ACCESS TO TEACHER MENTOR}

1. If available (many people compete for my mentor's time)

2. If available (at a regular time each week)

3. On demand (whenever I feel there is a need) but very briefly

4. On demand (whenever I feel there is a need) for as long as I need

Factor 6: TEACHING MENTOR (Medium of interaction)

1. Online

2. Meet at another school

3. Through telephone or videoconferencing

4. Meet at my school

Factor 7: TEACHING MENTOR (Focus of mentoring support)

1. Support for classroom management

2. Support in programming and assessment strategies

3. Support for career planning

4. Support in managing parents and community

Factor 8: ACCESS TO GOVERNMENT-SPONSORED^ ${ }^{\wedge}$ RESOURCES (MEDIUM) $^{-1}$

1. Hard copy documents

2. Videoconferencing

3. Web-based resources

4. Personal interaction

Factor 9: FOCUS OF GOVERNMENT-BASED^ ${ }^{\wedge}$ RESOURCES

1. Legal requirements (eg employee rights and responsibilities; leave access; pay issues; welfare)

2. Teaching and learning

3. Professional development to support accreditation

4. Curriculum requirements

Factor 10: PROFESSIONAL DEVELOPMENT TO ACHIEVE PROFESSIONAL TEACHING STANDARDS

1. In-school collegial professional support

2. On-line on time professional learning

3. Attendance at program/workshop/conference

4. No specific professional development to achieve Professional Teaching Standards

$\wedge$ Note: In the experiment, the word 'government-based' was replaced with the acronym for Department of Education and Training, 'DET'

Respondents would be familiar with this acronym as they were all DET employees, invited by DET to undertake the survey used in the research, and featured in the survey introduction. 
Table 2: Actual Experience of ECTs in Schools in relation to existing support

\begin{tabular}{|c|c|c|c|c|c|}
\hline 1. Affirmation and Inclusion & $\begin{array}{c}\text { All ECTs } \\
n=336\end{array}$ & $\begin{array}{c}\text { Stayers } \\
n=254 \\
(76 \%)\end{array}$ & $\begin{array}{c}\text { Leavers } \\
n=82 \\
(24 \%) \\
\end{array}$ & \multicolumn{2}{|c|}{$\begin{array}{c}\text { Significant } \\
\text { difference } \\
\text { (p-value) }\end{array}$} \\
\hline Recognition personal milestones & 8.93 & 7.87 & 12.20 & 0.28 & \\
\hline Professional recognition & 14.88 & 14.57 & 15.85 & 0.78 & \\
\hline Professional Voice & 47.62 & 49.21 & 42.68 & 0.30 & \\
\hline Executive interest & 28.57 & 28.35 & 29.27 & 0.87 & \\
\hline \multicolumn{6}{|l|}{ 2. Teaching Resources } \\
\hline Physical sharing & 36.90 & 40.16 & 26.83 & 0.02 & $*$ \\
\hline Electronic sharing & 19.94 & 19.69 & 20.73 & 0.83 & \\
\hline ICT support & 13.99 & 16.14 & 7.32 & 0.01 & $*$ \\
\hline No sharing & 29.17 & 24.02 & 45.12 & 0.00 & $* *$ \\
\hline \multicolumn{6}{|c|}{ 3. Working with Experienced Teachers } \\
\hline Cooperative planning & 44.35 & 48.03 & 32.93 & 0.01 & $* *$ \\
\hline Co-teaching & 4.76 & 5.51 & 2.44 & 0.15 & \\
\hline Collaborative observation & 3.57 & 4.33 & 1.22 & 0.06 & \\
\hline Isolation & 47.32 & 42.13 & 63.41 & 0.00 & $* *$ \\
\hline \multicolumn{6}{|c|}{ 4. Planned Conversations About Teaching } \\
\hline With beginning teachers & 24.11 & 24.41 & 23.17 & 0.80 & \\
\hline With supervisor & 34.23 & 37.01 & 25.61 & 0.03 & $*$ \\
\hline With mentor & 15.48 & 16.54 & 12.20 & 0.27 & \\
\hline Limited & 26.19 & 22.05 & 39.02 & 0.00 & $* *$ \\
\hline \multicolumn{6}{|l|}{ 5. Mentor - Accessibility } \\
\hline Competitive & 27.08 & 21.65 & 43.90 & 0.00 & $* *$ \\
\hline Regularly & 7.14 & 6.69 & 8.54 & 0.55 & \\
\hline Brief on demand & 31.25 & 31.50 & 30.49 & 0.85 & \\
\hline Lengthy on demand & 34.52 & 40.16 & 17.07 & 0.00 & $* *$ \\
\hline \multicolumn{6}{|c|}{ 6. Mentor - Medium of Interaction } \\
\hline Online & 5.36 & 4.33 & 8.54 & 0.15 & \\
\hline At another school & 1.49 & 1.18 & 2.44 & 0.43 & \\
\hline Phone & 1.79 & 1.57 & 2.44 & 0.59 & \\
\hline At school & 91.37 & 92.91 & 86.59 & 0.07 & \\
\hline \multicolumn{6}{|l|}{ 7. Mentor - Focus of Support } \\
\hline Classroom management & 39.29 & 39.37 & 39.02 & 0.95 & \\
\hline Programming \& assessment & 42.86 & 44.49 & 37.80 & 0.21 & \\
\hline Career planning & 9.23 & 8.66 & 10.98 & 0.48 & \\
\hline Parents \& community & 8.63 & 7.48 & 12.20 & 0.16 & \\
\hline \multicolumn{6}{|l|}{ 8. External Resources (Medium) } \\
\hline Hard copy & 15.48 & 15.35 & 15.85 & 0.90 & \\
\hline Videoconferencing & 0.00 & 0.00 & 0.00 & n.a & n.a \\
\hline Web-based & 80.65 & 81.50 & 78.05 & 0.43 & \\
\hline Personal & 3.87 & 3.15 & 6.10 & 0.21 & \\
\hline \multicolumn{6}{|l|}{ 9. External Resources (Focus) } \\
\hline Legal & 10.71 & 9.45 & 14.63 & 0.14 & \\
\hline Teaching \& learning & 46.73 & 49.21 & 39.02 & 0.05 & * \\
\hline Professional development & 10.42 & 11.02 & 8.54 & 0.41 & \\
\hline Curriculum & 32.14 & 30.31 & 37.80 & 0.13 & \\
\hline \multicolumn{6}{|c|}{ 10. Professional Development Support } \\
\hline In-school & 29.46 & 30.31 & 26.83 & 0.45 & \\
\hline Online & 0.89 & 0.39 & 2.44 & 0.13 & \\
\hline Workshop & 55.65 & 57.09 & 51.22 & 0.25 & \\
\hline None & 13.99 & 12.20 & 19.51 & 0.06 & \\
\hline
\end{tabular}

Notes: All figures listed in percentage terms; */** significant at the $95 / 99 \%$ level. 
Table 3: Predicted Latent Preference and Scale (Variance) Class Membership

\begin{tabular}{|c|c|c|c|c|c|c|c|}
\hline & & \multicolumn{3}{|c|}{$\begin{array}{c}\text { Scale } \\
\text { (Class } 1 \text { vs. 2) }\end{array}$} & \multicolumn{3}{|c|}{$\begin{array}{c}\text { Preference } \\
\text { (Class } 1 \text { vs. 2) }\end{array}$} \\
\hline & & Est. & p-value & sig. & Est. & p-value & sig. \\
\hline & Intercept & - & - & - & 0.137 & 0.621 & \\
\hline \multirow{3}{*}{$\begin{array}{l}\text { Plans for } \\
\text { next } 12 \\
\text { months }\end{array}$} & Plan to remain & 2.258 & 0.002 & $* *$ & 0.833 & 0.003 & $* *$ \\
\hline & Plan to leave & -2.153 & 0.011 & $*$ & -0.356 & 0.185 & \\
\hline & Other & -0.104 & 0.839 & & -0.477 & 0.064 & \\
\hline \multirow{3}{*}{$\begin{array}{l}\text { Learning } \\
\text { Disabilities }\end{array}$} & Majority of my time & 2.843 & 0.009 & $* *$ & 0.930 & 0.016 & $*$ \\
\hline & One among many & -0.497 & 0.264 & & -0.037 & 0.824 & \\
\hline & No & -2.346 & 0.005 & $* *$ & -0.893 & 0.006 & $* *$ \\
\hline \multirow{2}{*}{ Gender } & Male & -1.064 & 0.020 & $*$ & 0.041 & 0.883 & \\
\hline & Female & 1.064 & 0.020 & $*$ & -0.041 & 0.883 & \\
\hline \multirow{5}{*}{ Education } & MSc or PhD & 2.778 & 0.011 & $*$ & 0.969 & 0.028 & $*$ \\
\hline & Grad Dip & -2.831 & 0.003 & $* *$ & -0.672 & 0.065 & \\
\hline & Bachelor & 0.053 & 0.889 & & -0.297 & 0.207 & \\
\hline & $\%$ of sample in Class 1 & \multicolumn{3}{|c|}{$74.43 \%$} & \multicolumn{3}{|c|}{$67.22 \%$} \\
\hline & $\%$ of sample in Class 2 & \multicolumn{3}{|c|}{$25.57 \%$} & \multicolumn{3}{|c|}{$32.78 \%$} \\
\hline
\end{tabular}

Notes: */** significant difference at the $95 \% / 99 \%$ level. 
Table 4: Parameter Estimates for ECT Factors: Preference by Class

\begin{tabular}{|c|c|c|c|c|c|c|c|c|}
\hline \multirow[b]{2}{*}{ Model Effects } & \multicolumn{3}{|c|}{$\begin{array}{c}\text { Preference Class } 1 \\
\text { ('Stayers') }\end{array}$} & \multicolumn{3}{|c|}{$\begin{array}{c}\text { Preference Class } 2 \\
\text { ('Leavers') }\end{array}$} & \multicolumn{2}{|c|}{$\begin{array}{c}\text { Difference } \\
\text { between classes }\end{array}$} \\
\hline & Est. & z-value & Sig. & Est. & z-value & Sig. & Est. & Sig. \\
\hline Fixed Intercept (current) & -2.302 & -8.792 & $x$ & -4.681 & -3.882 & $x$ & -4.91 & $*$ \\
\hline Random Intercept (current) & 2.615 & 12.747 & $\checkmark$ & -8.558 & -5.139 & $\mathbf{x}$ & 17.886 & $*$ \\
\hline \multicolumn{9}{|l|}{ 1. Affirmation and inclusion } \\
\hline Recognition personal & -0.176 & -2.502 & $x$ & -1.408 & -4.457 & $x$ & 1.955 & \\
\hline Professional recognition & 0.084 & 1.225 & & -0.225 & -0.773 & & 1.998 & \\
\hline Professional Voice & 0.069 & 0.980 & & 1.442 & 3.706 & $\checkmark$ & -2.726 & $*$ \\
\hline Executive interest & 0.023 & 0.332 & & 0.191 & 0.876 & & -0.544 & \\
\hline \multicolumn{9}{|l|}{ 2. Teaching Resources } \\
\hline Physical sharing & 0.192 & 2.954 & $\checkmark$ & 0.452 & 2.061 & $\checkmark$ & 0.893 & \\
\hline Electronic sharing & 0.343 & 5.126 & $\checkmark$ & 0.908 & 3.646 & $\checkmark$ & 1.480 & \\
\hline ICT support & 0.213 & 3.005 & $\checkmark$ & 1.356 & 3.774 & $\checkmark$ & -0.769 & \\
\hline No sharing & -0.748 & -9.472 & $x$ & -2.716 & -5.718 & $x$ & -3.754 & $*$ \\
\hline \multicolumn{9}{|c|}{ 3. Working with experienced teachers } \\
\hline Cooperative planning & 0.198 & 2.870 & $\checkmark$ & 1.550 & 4.435 & $\checkmark$ & -1.565 & \\
\hline Co-teaching & -0.023 & -0.310 & & 1.298 & 4.004 & $\checkmark$ & -4.314 & $*$ \\
\hline Collaborative observation & 0.277 & 3.742 & $\checkmark$ & -0.259 & -0.972 & & 4.714 & $*$ \\
\hline Isolation & -0.451 & -5.992 & $x$ & -2.589 & -5.645 & $x$ & -0.347 & \\
\hline \multicolumn{9}{|c|}{$\begin{array}{l}\text { 4. Planned conversations about } \\
\text { teaching }\end{array}$} \\
\hline With beginning teachers & 0.161 & 2.457 & $\checkmark$ & -0.347 & -1.467 & & 3.924 & $*$ \\
\hline With supervisor & 0.149 & 2.138 & $\checkmark$ & 0.517 & 1.722 & & 0.416 & \\
\hline With mentor & 0.109 & 1.521 & & 0.357 & 1.487 & & 0.034 & \\
\hline Limited & -0.419 & -5.877 & $x$ & -0.527 & -1.981 & & -3.896 & $*$ \\
\hline \multicolumn{9}{|l|}{ 5. Teaching Mentor Access } \\
\hline Competitive & -0.057 & -0.827 & & -0.784 & -2.796 & $x$ & 1.969 & \\
\hline Regularly & 0.043 & 0.624 & & -0.335 & -1.451 & & 2.075 & $*$ \\
\hline Brief on demand & -0.075 & -1.079 & & 0.363 & 1.569 & & -2.648 & $*$ \\
\hline Lengthy on demand & 0.089 & 1.238 & & 0.755 & 2.933 & $\checkmark$ & -1.695 & \\
\hline \multicolumn{9}{|l|}{ 6. Mentor Medium } \\
\hline Online & -0.205 & -2.861 & $x$ & 0.560 & 1.806 & & -4.667 & $*$ \\
\hline At another school & -0.177 & -2.434 & $x$ & 0.007 & 0.023 & & -2.457 & $*$ \\
\hline Phone & -0.028 & -0.380 & & -0.034 & -0.102 & & -0.278 & \\
\hline At school & 0.410 & 5.751 & $\checkmark$ & -0.533 & -2.070 & $x$ & 7.821 & $*$ \\
\hline \multicolumn{9}{|c|}{ 7. Mentor Focus of Discussions } \\
\hline Classroom management & 0.181 & 2.712 & $\checkmark$ & 0.598 & 2.57 & $\checkmark$ & 0.142 & \\
\hline Programming \& assessment & -0.012 & -0.170 & & 1.314 & 4.344 & $\checkmark$ & -4.514 & $*$ \\
\hline Career planning & -0.004 & -0.060 & & -1.323 & -3.41 & $x$ & 3.350 & $*$ \\
\hline Parents \& community & -0.165 & -2.284 & $x$ & -0.589 & -1.88 & & -0.404 & \\
\hline \multicolumn{9}{|c|}{ 8. External Resources: Medium } \\
\hline Hard copy & 0.093 & 1.414 & & -0.640 & -1.988 & & 3.402 & $*$ \\
\hline Videoconferencing & -0.211 & -2.967 & $x$ & 0.332 & 1.211 & & -4.178 & $*$ \\
\hline Web-based & -0.020 & -0.273 & & 1.162 & 2.83 & $\checkmark$ & -3.103 & $*$ \\
\hline Personal & 0.137 & 1.844 & & -0.854 & -2.398 & $x$ & 4.242 & $*$ \\
\hline \multicolumn{9}{|l|}{ 9. External Resources: Focus } \\
\hline Legal & -0.216 & -3.057 & $x$ & -1.075 & -3.574 & $x$ & 0.517 & \\
\hline Teaching \& learning & 0.073 & 1.136 & & 0.647 & 2.201 & $\checkmark$ & -1.065 & \\
\hline Professional development & -0.026 & -0.373 & & 0.457 & 1.767 & & -2.140 & $*$ \\
\hline Curriculum & 0.169 & 2.55 & $\checkmark$ & -0.029 & -0.127 & & 2.677 & $*$ \\
\hline \multicolumn{9}{|c|}{ 10. Professional Development } \\
\hline In-school & -0.065 & -0.962 & & 1.028 & 2.879 & $\checkmark$ & -3.841 & $*$ \\
\hline Online & -0.052 & -0.689 & & 0.700 & 1.858 & & -2.547 & $*$ \\
\hline Workshop & 0.311 & 4.540 & $\checkmark$ & 0.454 & 1.801 & & 2.739 & $*$ \\
\hline None & -0.194 & -2.446 & $x$ & -2.181 & -3.099 & $x$ & 0.653 & \\
\hline
\end{tabular}


Figure 1: Example of a Choice Scenario

\begin{tabular}{|c|c|c|}
\hline Scenario 1 & & \\
\hline Features of Position & Position A & Position B \\
\hline 1. Affirmation and inclusion & $\begin{array}{l}\text { Greeting and enquiries from executive staff } \\
\text { about how you're going (interest shown) }\end{array}$ & $\begin{array}{l}\text { Recognition (e.g. via emails; announcements) of } \\
\text { activities/achievements in and outside of class } \\
\text { (e.g. excursions; accreditation progress) }\end{array}$ \\
\hline 2. Teaching resources & $\begin{array}{l}\text { Support for the use of computers in classrooms } \\
\text { and in teaching and learning programs }\end{array}$ & $\begin{array}{c}\text { Pigeon hole or "common drawer" allowing } \\
\text { shared access to other teachers' and/or school } \\
\text { resources/materials }\end{array}$ \\
\hline $\begin{array}{l}\text { 3. Working with more } \\
\text { experienced teachers }\end{array}$ & $\begin{array}{l}\text { Working together collaboratively with } \\
\text { experienced teacher by observing and being } \\
\text { observed in classroom }\end{array}$ & $\begin{array}{c}\text { Cooperative planning for teaching and learning } \\
\text { (Lesson preparation, design of teaching \& } \\
\text { assessment tasks) }\end{array}$ \\
\hline $\begin{array}{l}\text { 4. Planned professional } \\
\text { conversations about teaching } \\
\text { practice }\end{array}$ & $\begin{array}{l}\text { With other beginning teachers at my school or at } \\
\text { other schools in similar roles, subjects or stages }\end{array}$ & With my mentor \\
\hline 5. Access to mentor & $\begin{array}{l}\text { If available (many people compete for my } \\
\text { mentor's time) }\end{array}$ & $\begin{array}{c}\text { On demand (whenever I feel there is a need) but } \\
\text { very briefly }\end{array}$ \\
\hline $\begin{array}{l}\text { 6. Mentor (Medium of } \\
\text { interaction) }\end{array}$ & Meet at another school & Meet at another school \\
\hline $\begin{array}{l}\text { 7. Mentor (Focus of mentoring } \\
\text { support) }\end{array}$ & Support in managing parents and community & $\begin{array}{c}\text { Support in programming and assessment } \\
\text { strategies }\end{array}$ \\
\hline $\begin{array}{l}\text { 8. Access to DET resources } \\
\text { (medium) }\end{array}$ & Hard copy documents & Web-based resources \\
\hline 9. Focus of DET resources & Teaching and learning & Curriculum requirements \\
\hline $\begin{array}{l}\text { 10. Professional development } \\
\text { to achieve professional } \\
\text { teaching standards }\end{array}$ & On-line on time professional learning & $\begin{array}{c}\text { No specific professional development to achieve } \\
\text { Professional Teaching Standards }\end{array}$ \\
\hline
\end{tabular}

